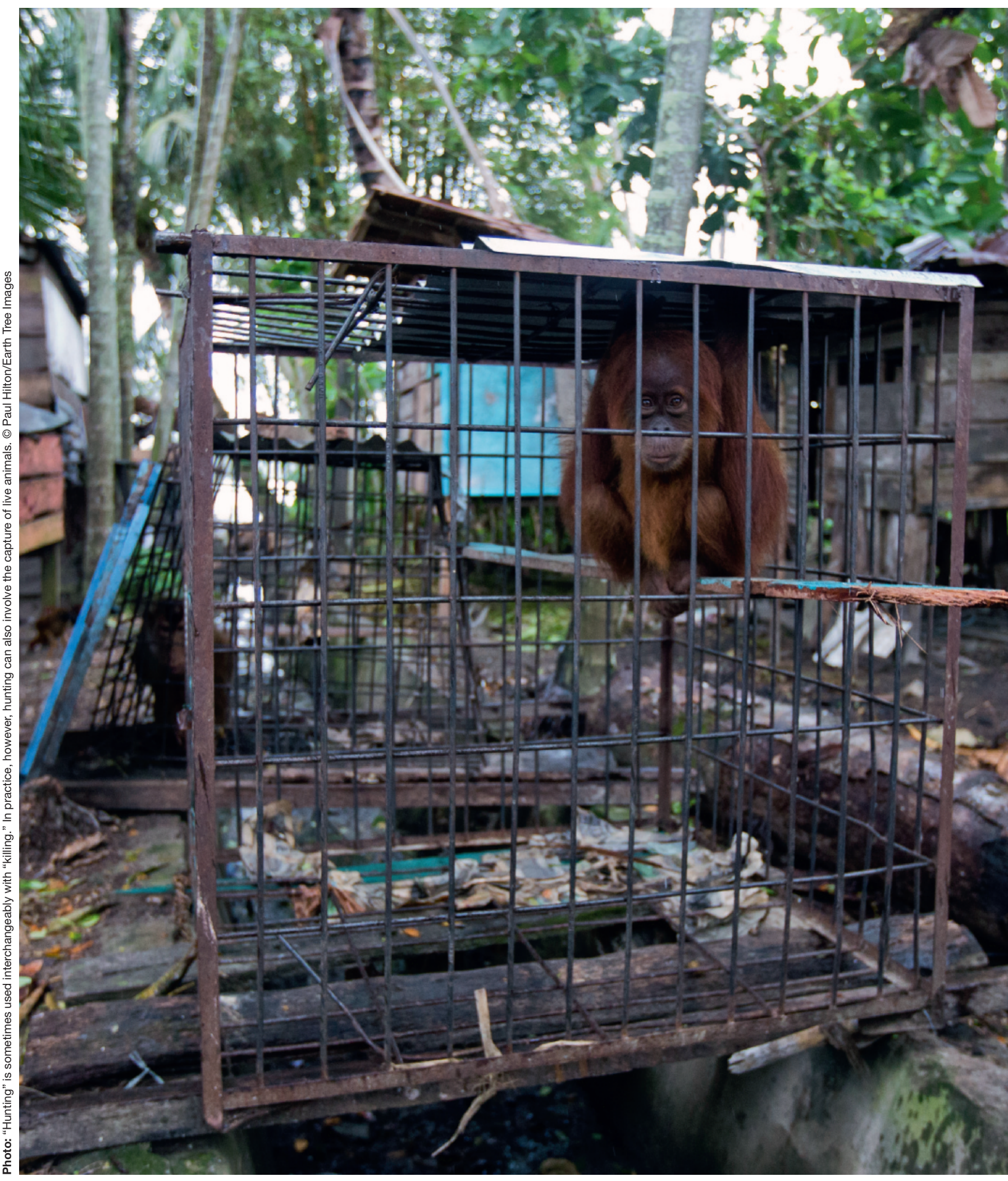




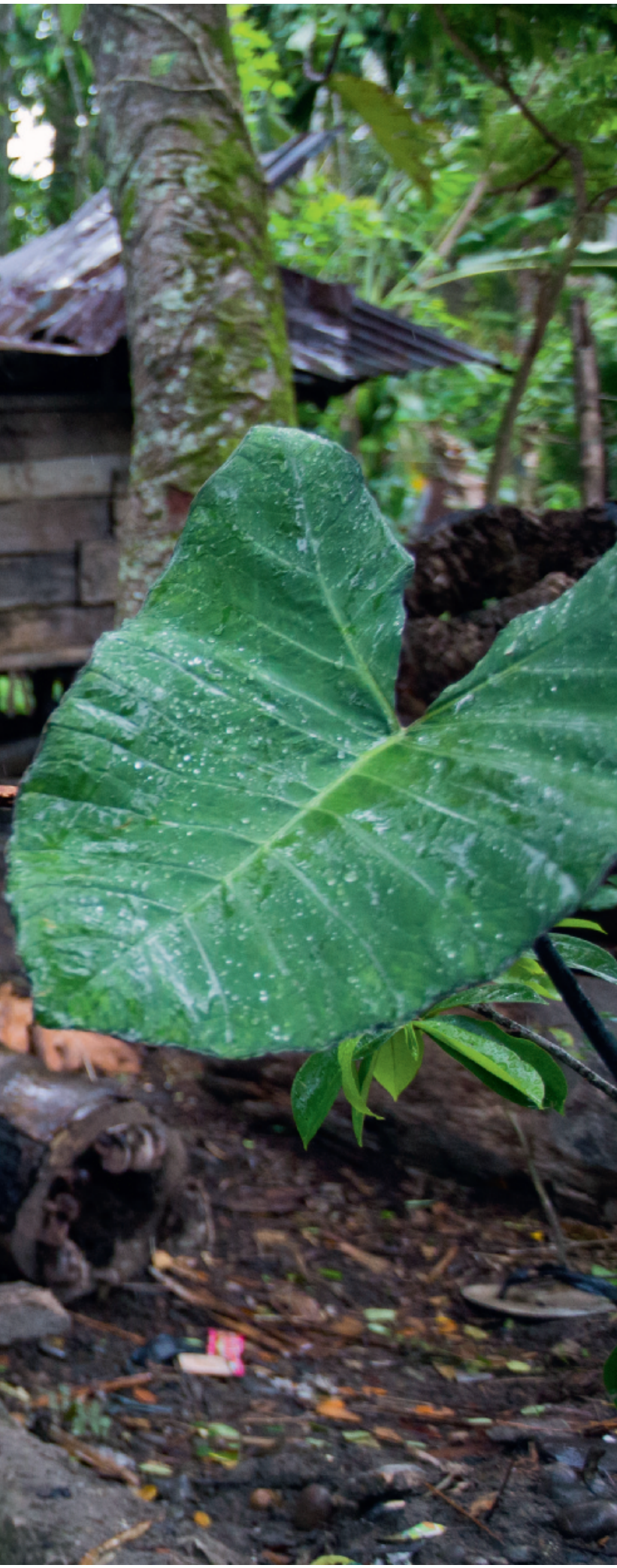

CHAPTER 1

\section{The Impact of Killing, Capture and Trade on Apes and their Habitat}

\section{Introduction}

The hunting of apes is not a new threat: fossils and archaeological remains show that people have hunted all ape taxa since they started living in ape habitat. In Asia, hunting by humans appears to have played a part in the decline of the orangutan after the late Pleistocene, which ended about 11,700 years ago, and gibbon skeletons were discovered in a 2,00o-year-old Chinese tomb (Spehar et al., 2018; Turvey et al., 2018).

What is new, however, is the scale of hunting, and its direct negative impact on the conservation status of apes, even though the hunting of apes is illegal in all range states. (Meijaard et al., 2010b). On both continents where wild apes are found todayAfrica and Asia-hunting pressure escalated 
with the introduction of long-distance weapons such as blowpipes and shotguns, which allow hunters to be more effective, and with the invention of snares, which permit them to cover a wider area for longer periods of time (Marshall et al., 2006; Meijaard et al., 2010a).

The term "hunting" is sometimes used interchangeably with "killing." In practice, however, hunting can also involve the capture of live animals. With respect to the trade in apes, hunting is the first step in a chain of illegal activities that supply meat, parts and live captures to local, national and international markets. The trade in ape meat and parts mainly meets the demand for food, medicine and fetishes; the trade in live animals, including infants captured after their parents are killed, supplies the pet, tourism and entertainment industries. People also kill apes due to "competition for resources," to "retaliate" against animals for raiding crops or simply for being present in plantations or villages, and for perceived personal and community safety reasons. Some apes are killed or maimed unintentionally, such as when hunters inadvertently trap apes in snares set for other animals (see Box 1.1). To underscore these nuances, this volume uses the terms hunting, killing, capture and trade to refer to distinct threats to apes and their survival. It also uses the term poaching to cover illegal hunting, killing, capturing or taking of wildlife in violation of local or international wildlife conservation laws. Indirect impacts of hunting include injury and maiming,
BOX 1.1

\section{Snaring of Chimpanzees}

Snaring is a comparatively cheap, indiscriminate trapping method often aimed at small or medium-sized mammals. Snares include wire or nylon traps, as well as the more dangerous metal "mantraps" that typically trap the entire foot or leg of an animal. They are usually set either in the forest to catch game or around agricultural fields to protect crops from wildlife.

Death and mutilation resulting from snaring are relatively common in great apes, especially among the more terrestrial African apes. While there is variation across sites, mantraps tend to cause the most severe injuries. Between 2008 and 2016 in Bulindi, Uganda, five mature chimpanzees incurred injuries from large, steel mantraps (McLennan et al., 2012). ${ }^{1}$ Many more chimpanzees at various sites, especially in Budongo Forest Reserve, Uganda, have displayed injuries caused by snares (Reynolds, 2005). In the lower Kinabatangan region of Borneo, a couple of orangutans were recently caught in snares as they moved on the ground across agricultural landscapes and forest patches (HUTAN-Kinabatangan Orangutan Conservation Programme, unpublished data, 2019). Gibbons are spared snaring due to their arboreal lifestyle. Among apes, chimpanzees are the most frequently documented victims of snaring; while all subspecies of chimpanzee are affected, snaring rates vary regionally, depending on local hunting practices.

To date, there has been no evidence of the snaring of chimpanzees in Senegal, as the practice of snaring is uncommon and hunting is mainly performed using guns. In contrast, chimpanzees in Uganda are at high risk. More than one-third of an estimated 700 chimpanzees living in the Budongo Forest Reserve-where $12 \%$ of farmers have reported using snareshave been maimed as a result of wire-snare injuries, and an estimated two to three individuals die annually as a result of snaring (Reynolds, 2005; Tumusiime and Tweheyo, 2010). Similarly, in Kibale National Park, 16 (31\%) of the Sebitoli community of 51 chimpanzees exhibit limb malformations due to snare injuries (Cibot et al., 2016). In Uganda's Hoima district, in the forest-agriculture matrix stretching between the Budongo and Bugoma forest reserves (that is, Bulindi), mantraps severely injured an average of at least two chimpanzees every year from 2007 to 2011; overall, these individuals had a $33 \%$ risk of dying from their wounds (McLennan et al., 2012).

When caught in a snare, an individual will pull on it to remove a trapped limb or dislodge the snare. In the case of wire snares, the wire then tightens around the trapped body part, cutting off blood flow and causing an infection, which is often followed by necrosis and permanent loss of a limb or limb malformation. Severely affected adult females in Budongo spend more time in smaller parties, possibly to reduce the risk of competition with others and due to their diminished ability to follow large traveling parties (Hermans, 2011). Indeed, these females travel less, spend more time in the trees and also carry their infants less often, especially as these mature and became heavier to carry (Munn, 2006). Injured individuals - especially ones who suffered the loss of limbs - may encounter difficulties accessing and processing foods; they may also lose their social rank and hence be further limited in the competition for access to food (Byrne and Stokes, 2002; Cibot et al., 2016).

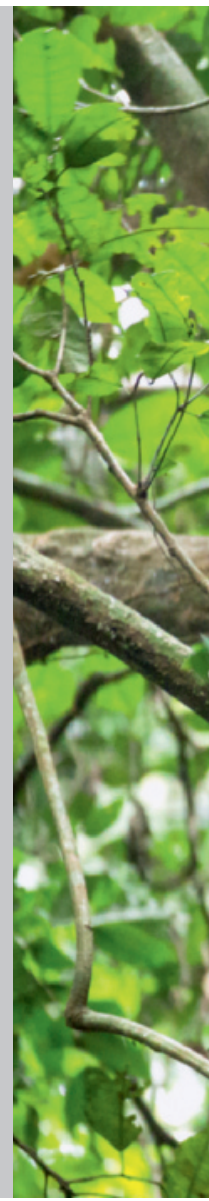


which can result in an individual's death, and the social-ecological and psychological impacts of hunting activities on survivors.

The hunting of apes is one of the most important drivers of their extinction. Given that the International Union for Conservation of Nature (IUCN) lists all ape species as either "critically endangered" or "endangered"-except for the "vulnerable" eastern hoolock gibbon (Hoolock leuconedys) - the scale of hunting is a key determinant of their survival in the wild (Brockelman and Geissmann, 2019).

This chapter explores direct and indirect impacts of hunting, why apes are especially vulnerable to hunting and the risks of hunting to human health (see Box 1.5). It also identifies knowledge gaps that urgently need to be filled so that this threat may be tackled effectively.

The key findings include:

- One of the most important drivers of extinction for apes is hunting, specifically when it results in the removal of apes from the wild through killing and capture.

- People kill and capture apes for various reasons. They kill apes for their meat and parts, to facilitate the capture of infants for the live animal trade, to protect their crops or property from real or perceived threats, to feel safer, and for "sport"; they capture apes for the live animal trade, which supplies apes as pets, zoo animals, photo props and other tourism accessories, and as attractions
Photo: Death and mutilation resulting from snaring are relatively common in great apes. An elder female bonobo tries to remove a wire snare from the hand of an adolescent female as other females look on. Wamba, DRC. (C) Takesh Furuichi, Wamba Committee for Bonobo Research

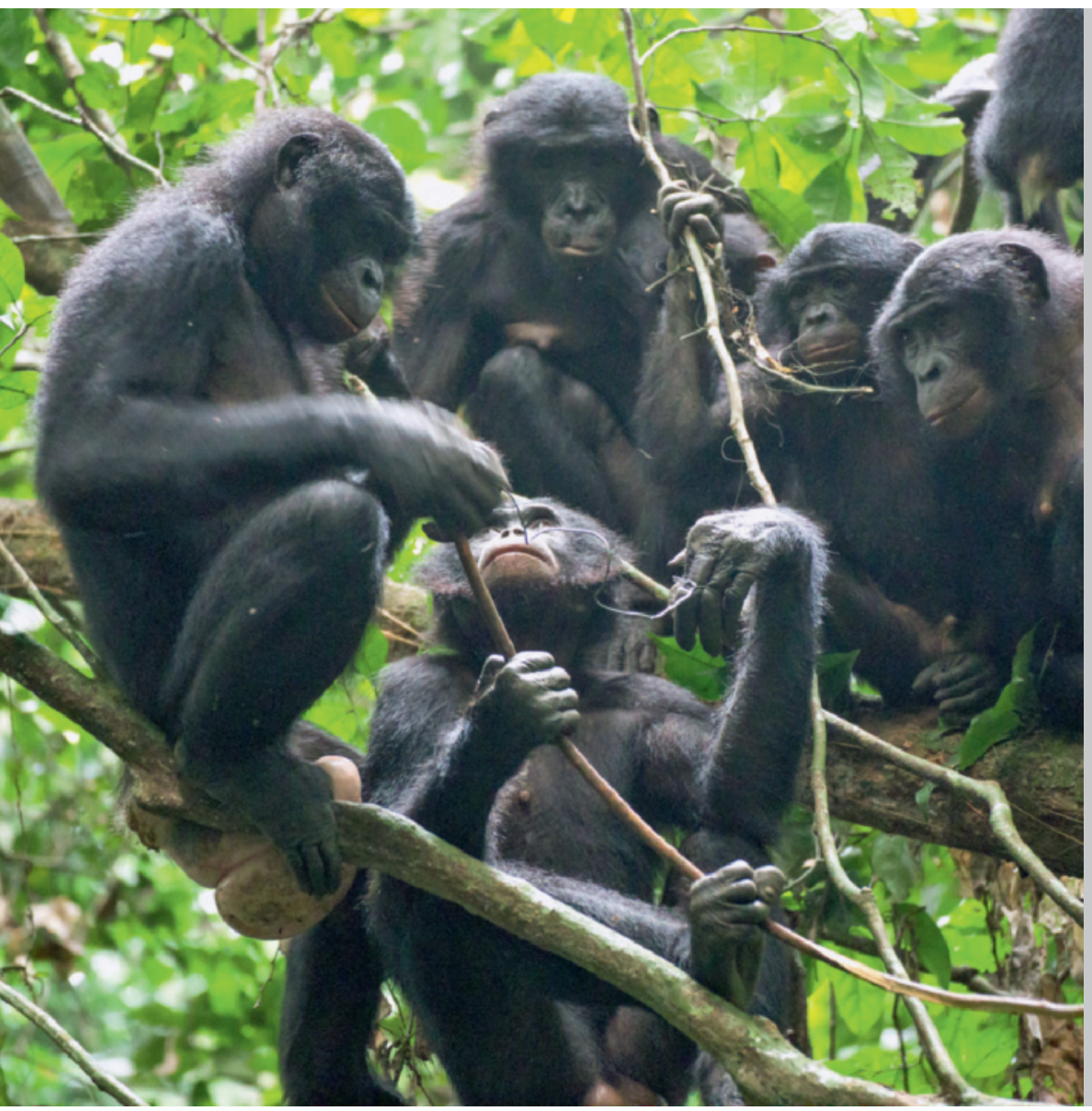

In addition, these individuals may experience a reduction in their immune system function, as high stress or lower-quality nutrition may affect immunocompetence in fighting disease or parasitic infections (Yersin et al., 2017). Individuals are not only more susceptible to intestinal parasites, but they are also more vulnerable to external parasites such as ticks and fleas-either because they are less able to self-groom if their hands are affected, or because they tend to reuse nests (which may harbor fleas and ticks, as well as contaminated fecal matter) since they are less able to build a new nest every night, a norm among great apes (Plumptre and Reynolds, 1997; Yersin et al., 2017).

Remarkably, members of some chimpanzee communities, such as Bossou in Guinea, have the ability and the knowledge to disable wire snares (Ohashi and Matsuzawa, 2011; Sugiyama and Humle, 2011). Mountain gorillas in Rwanda have exhibited similar behavior (V. Vecellio, personal communication, 2019). Since research indicates that this behavior is transmitted socially, the disappearance of primed individuals is expected to lead to a loss of knowledge that might prevent further snaring fatalities and injuries. 


\section{By hunting \\ apes, people expose \\ themselves as well \\ as the apes to the \\ risk of disease \\ transmission, with \\ serious implications \\ for the health of \\ both humans and \\ apes.}

for amusement parks and other entertainment venues.

- Apes are particularly vulnerable to the effects of hunting because they have slow reproductive rates and a long time to maturity, which result in low growth rates that are exacerbated when even a few individuals are removed from the wild.

- Local, hunting-driven ape decline or extinction can have a severe impact on seed dispersal, which is critical to maintaining tree species diversity and ecosystem health.

- By hunting apes, people expose themselves as well as the apes to the risk of disease transmission, with serious implications for the health of both humans and apes.

- More data are needed for an accurate assessment of the scale of ape hunting and its impact on the long-term survival of intact populations and their ecosystems.

\section{Direct Impacts of Hunting on Species Decline: Population Size and Social Consequences}

\section{Overview}

Hunting has long been acknowledged as a major threat to ape populations in Africa; more recently, it was also recognized as a main driver of extinction among orangutans in Borneo and in Sumatra (Abram et al., 2015; Davis et al., 2013; Meijaard et al., 2011a; Strindberg et al., 2018; Wich et al., 2012). Less is known about the impact of hunting on wild gibbon populations, but this activity has probably contributed to the decline in several populations, including the Hainan gibbon (Nomascus hainanus), Cao Vit gibbon (Nomascus nasutus), Gaoligong gibbon (Hoolock tianxing), Kloss's gibbon (Hylobates klossii) and eastern hoolock gibbon (Hoolock leuconedys) (Fan et al., 2013, 2017; Fellowes et al., 2008; Quinten et al., 2014; Wei et al., 2004; Yin et al., 2016). Hunting is also highly likely to affect other gibbon species, such as the Bornean white-bearded gibbon (Hylobates albibarbis) and moloch gibbon (Hylobates moloch) (Cheyne et al., 2016; Smith et al., 2018).

First and foremost, it is necessary to acknowledge the overall lack of understanding and knowledge concerning the actual offtake-that is, the precise number of apes removed from the wild due to hunting - and its impact for ape conservation. The direct impacts of hunting on ape populations are difficult to quantify simply because hunting is illegal and therefore its effects are challenging to measure. Nevertheless, it is important to distinguish between different types of hunting since the underlying causes are different in each case, although they may occur concurrently in a single area. The hunting of apes typically occurs for one of three reasons:

- For wild meat: This type of killing is largely limited to protected forests and forests that are exploited for timber or other resource extraction (Tranquilli et al., 2014). While hunters generally shoot apes to supply the wild meat trade, especially in urban centers (see Chapter 3), some killings are driven by the demand for ape meat for medicinal purposes or cultural ceremonies (see Chapter 2). Hunting for meat can also result in the unplanned capture of young apes; these orphans often end up in the illegal live trade.

- Due to "competition for resources" and other safety concerns: This type of hunting mainly happens in nonprotected forests and agricultural landscapes. It is the consequence of habitat loss and fragmentation, which displace apes or push them into people's orchards, 
gardens, cultivated fields and plantations in search of food or for dispersal. The trade in live infants is an opportunistic by-product of this type of hunting (Meijaard et al., 2011a). ${ }^{2}$

- To capture infants for the trade in live animals: Hunters who supply this trade are meeting the demand for apes that are to be used as pets, tourism accessories, zoo residents, and performers in amusement parks (Clough and May, 2018; Greengrass, 2015; see Chapter 4). As noted above, the capture of infants can also be an unintended consequence of hunting for meat or in response to safety concerns.

For all ape species, the direct impacts of hunting activities include the reduction of the overall abundance of any hunted population via the loss of individuals. Put another way, hunting causes group size to shrink and social groups to break down or collapse. Given the dearth of information on the offtake of apes-including the incidental count, meaning the number of apes killed for every targeted animal-it is difficult to quantify the impact of hunting activities.

In human-dominated landscapes, local people or industry players may see the presence of apes as a threat to their crops. Since great apes spend most of their time on the ground-much more than gibbons-they can learn how to use mosaic agricultural landscapes and thus survive in humandominated areas. Indeed, some species can adapt their diets and their social behavior to new ecological resources (Ancrenaz et al., 2015; McLennan and Hockings, 2014; Meijaard et al., 2010a; Seiler and Robbins, 2016). As a result, they increasingly compete with humans for the same resources, which can lead local people to capture or kill them as "mitigation" measures (Ancrenaz, Dabek and O'Neil, 2007; Baker, Milner-Gulland and Leader-Williams, 2012).

The removal of an infant ape from the wild generally involves the killing of the mother. Hunters may kill several mothers and infants to obtain one live infant for the pet trade. Estimates range from one to ten individuals killed to obtain a single live infant (Stiles et al., 2013). The range reflects variations in the social organization of the species, as well as the behavior exhibited towards humans. For example, adult female orangutans with unweaned offspring typically range by themselves, whereas gorillas are found in cohesive social groups of about ten individuals (Robbins and Robbins, 2018). Chimpanzees and bonobos live in larger communities of 20 to more than 100 individuals, but they have a fission-fusion grouping system, meaning that the entire community is almost never found together, but rather in parties (Furuichi, 2009). When threatened by poachers, chimpanzees and bonobos tend to flee, while an adult male leader of a gorilla group is likely to try to defend females and infants, increasing the likelihood that he will be killed (DoranSheehy et al., 2007). The killing of a silverback of a one-male group has significant knock-on effects, as other silverbacks are likely to kill his unweaned offspring when the adult females join other groups (Kalpers et al., 2003; Robbins et al., 2013; Watts, 1989).

In addition, hunting has consequences for the socioecology of remaining individuals through social stress, loss of local knowledge of the habitat or socially learned behaviors (see Box 1.1), and a reduction of the group's range if the animals start avoiding areas that are regularly hunted (Gruber et al., 2019; Kühl et al., 2019; van Schaik, 2002). While hunting can lead to the immediate death of individuals, it can also result in injury caused by bullet wounds or snaring. Such injuries may reduce the lifespan, breeding success and psychological wellbeing of affected individuals. The extent of the loss of injured individuals is unknown, as apes may survive the initial injury but succumb to it later because of wound infection or other impairments. Migration of 
TABLE 1.1

Number of Gibbons Held in Rescue Centers across Southeast Asia, per Species,
2015-16 (Excluding Zoos)

\begin{tabular}{|l|l|l|l|}
\hline Rescue center location & Common name & Species & Number \\
\hline Cambodia & Pileated gibbon & Hylobates pileatus & 25 \\
\hline India & Western hoolock & Hoolock hoolock & 10 \\
\hline Indonesia & Abbott's gray gibbon & Hylobates abbottii & $91^{*}$ \\
\cline { 2 - 4 } & Bornean gray gibbon & Hylobates funereus & \\
\hline & Müller's gibbon & Hylobates muelleri & \\
\hline & Agile gibbon & Hylobates agilis & 100 \\
\hline & Bornean white-bearded gibbon & Hylobates albibarbis & 100 \\
\hline & Kloss's gibbon & Hylobates klossii & 20 \\
\hline & Moloch gibbon & Hylobates moloch & 86 \\
\hline & Siamang & Symphalangus syndactylus & 160 \\
\hline Malaysia & Siamang & Symphalangus syndactylus & 25 \\
\hline Thailand & Lar gibbon & Hylobates lar & 80 \\
\hline & Pileated gibbon & Hylobates pileatus & 15 \\
\hline Viet Nam & Nomascus genus & Nomascus spp. & 35 \\
\hline
\end{tabular}

Note: * The starred number comprises three species; the total was not disaggregated.

Sources: Kheng et al. (2017); Nijman, Yang Martinez and Shepherd (2009); Smith et al. (2018)

Photo: The rapid growth and widespread use of social media facilitate the wildlife trade. Baby moloch gibbon for sale on social media. Source: screenshot from 2018 bullets or pellets to organs within the body can have a significant impact on individuals' survival, as can the loss of body partssuch as fingers, toes, a hand or a foot-due to snares (see Box 1.1).

There is an urgent need to quantify the actual extent, rate and impact of killing and capture. The task requires a more global and comprehensive approach. Currently, the limited available data are drawn from a few disparate studies undertaken in localities that cannot confidently be categorized as hotspots or areas of more moderate offtake (Marshall et al., 2006; Meijaard et al., 2012; Quinten et al., 2014; Yin et al., 2016). More work is also needed to evaluate and mitigate the impact of snaring on apes, including through anti-poaching patrols, snare removal teams, and awareness raising campaigns (see Chapters 5 and 6).

\section{The Scale of Hunting Pressure: Current Knowledge per Taxon}

\section{Gibbons}

The main direct threats to gibbons are habitat loss, degradation and fragmentation, infectious disease and killing, be it for wild meat or in the context of conflicts over cultivated food or other resources (Campbell, Cheyne and Rawson, 2015; Cheyne et al., 2016). The relative importance of these threats varies by taxon and location. In general, gibbons are not specifically targeted for wild meat, yet poached wild meat does include gibbon meat. No one knows precisely what impact hunting for wild meat is having on wild gibbon populations. What is clear is that wild meat hunting is having a more pronounced effect on gibbons in certain countries, including China, Lao People's 
Democratic Republic, Myanmar, Thailand, and Viet Nam, through habitat decline and population fragmentation. ${ }^{3}$ Gibbon populations in the Mentawai Islands of Indonesia are more likely to be targets of cultural hunting and the pet trade (Quinten et al., 2014; see Box 1.4 and Chapter 2). As described above, the killing of a mother may enable the opportunistic capture of infants, who are then supplied into the live animal trade.

A thorough understanding of local circumstances is required to address the main threats to gibbons. What is certain is that two species of gibbon-the Hainan and Gaoligong-have reached critically low numbers, in part due to hunting; urgent conservation measures are needed to protect these small, isolated populations (Bryant et al., 2017; Fan et al., 2017; Li et al., 2018; Liu et al., 1987; Wei et al., 2017). Offtake data are lacking and obtaining accurate numbers for

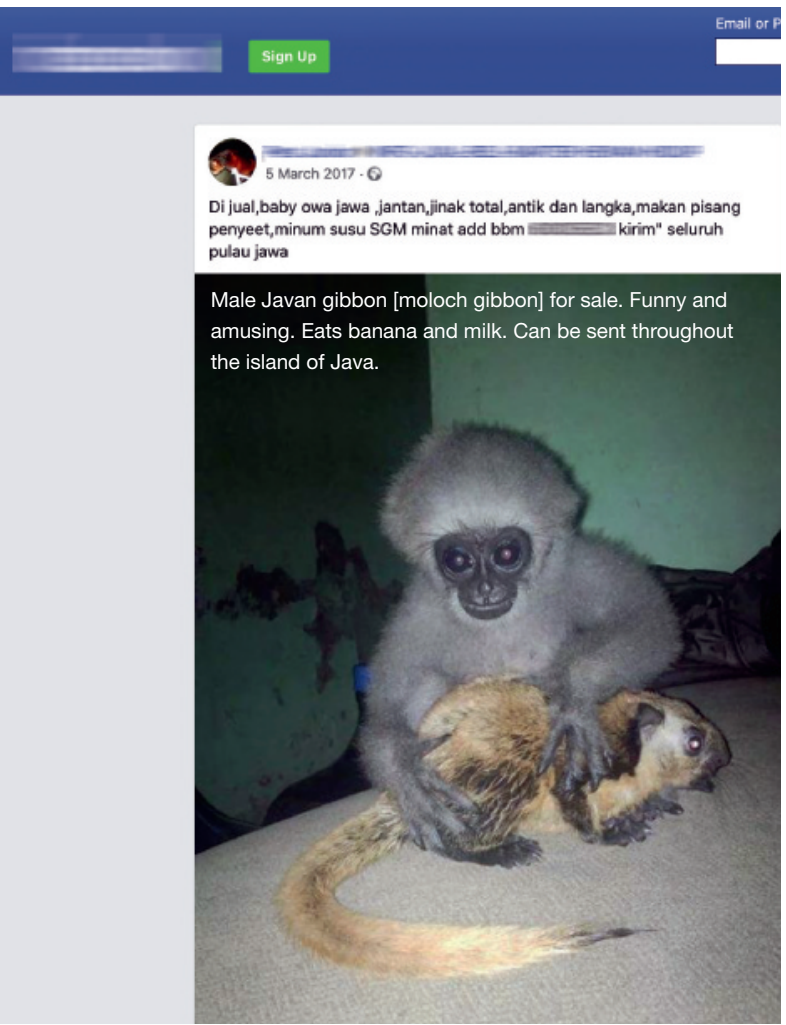

\section{$30 \times 1.2$}

\section{Gibbons for Sale on Social Media}

Facebook boasts 600 million daily active users in the Asia-Pacific region, its largest market (Soto Reyes, 2019). From 2016 to 2018, the photo-sharing app Instagram gained significant momentum, reaching 1 billion monthly active accounts, most of which are in Asia (Clement, 2019; Instagram, n.d.). The rapid growth and widespread use of social media facilitate the wildlife trade, often in undetected ways. Evidence points to Indonesia and Malaysia as the two habitat countries with the most prolific trade in wildlife, predominantly of very young animals servicing the illegal pet trade. Thailand tops the list for the use of wildlife as photo props for tourist selfies on beaches and in bars (Osterberg et al., 2015).

The inaccessibility of closed social media groups has implications for the control of such platforms. For security and privacy reasons, social media companies have exclusive control of the backend of their sites - that is, the data processing involved in the sending of messages, login verification, feeds, and storage. Since these companies are not technically the publishers of the content, however, they are not legally required to edit it, even if it is illegal. Nevertheless, Facebook has taken some steps to audit its content and Instagram is working with the World Wide Fund for Nature (WWF) and TRAFFIC to educate users and deter criminals from using the platform (Wagner, 2019; see Chapter 4, pp. 125-126).

The most effective ways to track the removal of gibbons is to monitor 1) sales on social media, 2) markets, 3) areas where gibbons (and other animals) are used as photo props, and 4) intake by rescue centers and zoos. It is more difficult to monitor how many individuals are kept as pets near forest sources. Preliminary surveys of gibbons for sale online in Indonesia via Facebook and Instagram found a total of 40 individual gibbons from 6 species available in a 3-month period, AprilJune 2017 (Smith and Cheyne, 2017). Further investigations in Malaysia and Myanmar, alongside additional research in Indonesia, ${ }^{4}$ indicate that gibbon species for sale on social media are native species. ${ }^{5}$

While putting gibbons up for sale is illegal and it is clear that gibbons are being extracted from the wild, the fact that the animals are not crossing international borders means that they are not covered by the Convention on International Trade in Endangered Species of Wild Fauna and Flora (CITES). Since captured gibbons remain in their countries and CITES is not violated, it is impossible for international law enforcement agencies such as INTERPOL to intervene. Meanwhile, there is insufficient political will in these countries to pursue traders and buyers who are violating national legislation.

This large-scale online sales network is currently under-studied, and work to tackle it is under-funded. Traders have a solid online presence, their websites are openly accessible, and sales are rife across social media (Facebook, Instagram and WhatsApp); nevertheless, prosecutions are limited. To be effective, a campaign would need to bring about a reduction in the demand for gibbons. One way to reach and counter the activities of vendors and potential buyers may be through novel educational narratives.

For more information on the use of social media to trade apes, see Chapter 4. 
gibbons held in rescue centers is difficult. Table 1.1 provides a general sense of the numbers based on previous publications and author interviews with gibbon rescue centers at the Orangutan Veterinary Advisory Group Meeting in July 2018 in Aceh, Indonesia; the data relate only to species held in the rescue centers (Commitante et al., 2018).

The significant number of gibbons available for sale on social media and used as photo props indicates that the extraction of infants from the wild is ongoing, and possibly increasing. The demand is fueled by the proliferation of online images of gibbons as pets (Smith and Cheyne, 2017; see Box 1.2 and Chapter 4).

\section{Orangutans}

Orangutans have been part of people's diet since the Pleistocene, as suggested by fossil evidence found in the Niah caves in Sarawak, Malaysia, where humans were active as far back as 45,000 years ago (Harrisson, 1966; Spehar et al., 2018). Over the following
BOX 1.3

\section{Orangutan Hunting in Borneo}

Recent analysis of population trends of Bornean orangutans indicates that the killing of individuals is one of the major factors leading to their decline, especially in the Indonesian part of Borneo, but also in certain parts of Sabah and Sarawak (Santika et al., 2017; Voigt et al., 2018).

Detailed, interview-based surveys confirm the severity of this threat. Borneo-wide social surveys of more than 5,000 respondents living in more than 500 villages - or about $10 \%$ of the villages of the entire island-show that an average of about 2,000 to 3,000 orangutans were killed annually over the average lifetime of the respondents (Davis et al., 2013; Meijaard et al., 2011a, 2011b). Further analysis of these data established that 750 to 1,800 individuals were killed in 2010 (Meijaard et al., 2011a).

In Kalimantan nearly one-fourth of the villages sampled as part of these surveys reported the killing of an orangutan in the year before the survey was undertaken (Abram et al., 2015). About $5 \%$ of all reliable respondents ( 232 of 4,732 persons) said that they had killed an orangutan during their lifetime (Davis et al., 2013; Meijaard et al., 2011a). The majority of these killings appear to have been opportunistic and very few respondents reported killing several individuals in the past, although one respondent claimed to have killed more than 70 orangutans, and another bragged about killing more than 100 .

Of the villagers who asserted that they had killed an orangutan, the majority (56\%) said their primary reason was securing access to meat and nearly one-fourth (23\%) said they felt threatened or that the animals were destroying people's crops. Respondents who did not cite food or conflict situations as their primary driver said they had killed apes accidentally while hunting for other animals (5\% of respondents), for the pet trade (3\%), for traditional medicine (3\%) or for "sport" hunting (3\%) (Davis et al., 2013).
In areas dominated by oil palm plantations and other crops, many people perceive orangutans as pests and kill them if they enter plantations (Davis et al., 2013). Individuals associated with industrial and smaller oil palm plantations account for about $20-25 \%$ of the killings in Kalimantan. By far more killings-about $60 \%$ of the total-occur in protected and non-protected forests where hunters kill game (Figure 1.1). In these areas, the likelihood that orangutans will be killed increases with the proportion of resident Christians, who do not have any taboos against consuming ape meat (Abram et al., 2015; Davis et al., 2013; see Box 1.4).

Based on these studies, the annual killing rates are significantly above the maximum offtake levels that can be withstood by viable populations in the long term. Population viability analysis suggests that if yearly offtakes of female orangutans exceed $1 \%$, a population will be driven towards extinction within a few decades (Marshall et al., 2009). The research suggests that for many affected populations annual offtake rates exceed $1 \%$ and can be as high as $4 \%$ (Davis et al., 2013; Meijaard et al., 2011a). While precise annual offtake rates may not be available, newspaper reports and confiscations indicate that significant numbers of orangutans are being killed-and that this threat needs to be taken seriously.

Since the factors that lead people to kill orangutans are complex-and potentially involve ethnicity, taboos, perceptions, types of habitat, and a lack of law enforcementmeasures designed to prevent killings are likely to have the greatest impact if they target specific groups with tailored messages, rather than a one-size-fits-all approach (Meijaard et al., 2011b). The enforcement of relevant laws, in particular, is woefully inadequate. Convictions for killing, acquiring, and trading in orangutans are nearly non-existent, although the governments of Indonesia and Malaysia recently prosecuted a few people for killing and trading in orangutans (J. Sherman, personal communication, 2019). 


\section{FIGURE 1.1}

\section{Borneo: Plantations, Protected and Unprotected Forest}

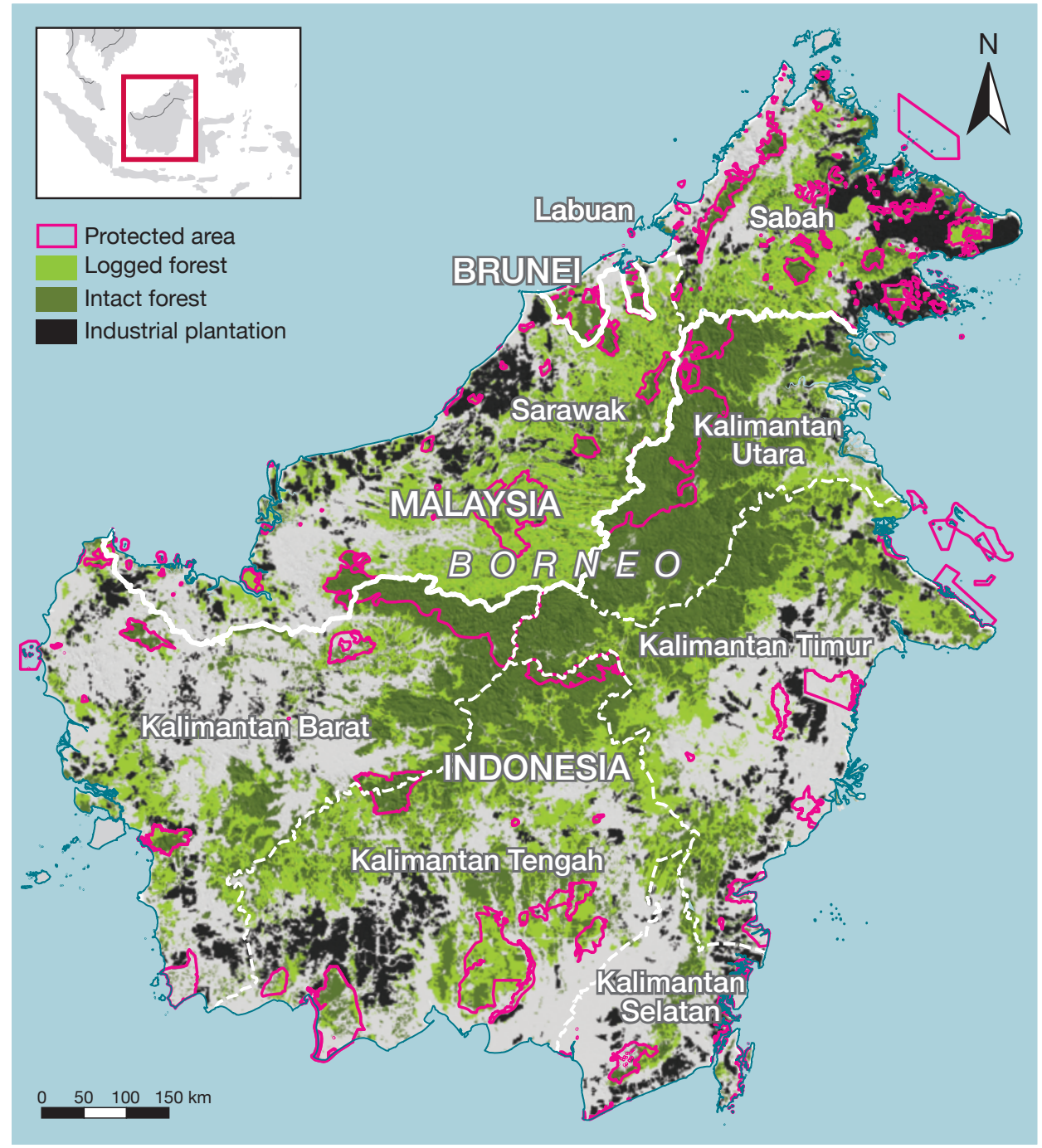

Sources: Adapted from Gaveau et al., 2014, p. 6 and UNEP-WCMC and IUCN, 2019.

millennia, the proportion of orangutan fragments in prehistoric deposits increased with the development of spears and arrows (in the late Pleistocene) and with the more recent arrival of blowpipe technology (4,000 years ago) (Spehar et al., 2018). During the past 300 years, powdered guns became widespread; they have played a key role in the drastic negative impact of hunting since colonial times (Goossens et al., 2006). One recent analysis shows that orangutan encounter rates in Borneo have declined six-fold since the early $18^{\text {th }}$ century (Meijaard et al., 2010b).

Today, hunting remains a serious threat for the Bornean and Sumatran orangutans. Together with habitat loss, hunting is a major driver of extinction for all these species, with the exception of the Tapanuli orangutan (Pongo tapanuliensis), whose single population lives in remote areas that are mostly 
Unlike in Africa, there is no established wild ape meat trade in Borneo; nevertheless, more than half of the orangutans killed on the island are hunted for their meat. surrounded by people who do not hunt (Nowak et al., 2017; Wich et al., 2019; see the Apes Overview). One survey indicates that in Borneo alone, roughly 2,000 to 3,000 orangutans were killed every year during the lifetimes of survey respondents (Meijaard et al., 2011a). The study also reveals that between 750 and 1,800 individuals were killed in Borneo in 2010 alone; these deaths represent more than $1 \%$ of the current estimated number of orangutans in the wild, a figure squarely above a "sustainable" harvest rate (see Box 1.3). Such killing estimates are higher than previously thought and are in accordance with the results of two recent studies that show a dramatic decline in orangutan numbers and abundance in Borneo between 1997 and 2015 (Santika et al., 2017; Voigt et al., 2018).

Unlike in Africa, there is no established wild ape meat trade in Borneo (Davis et al., 2013); nevertheless, more than half of the orangutans killed on the island are hunted for their meat. Indeed, orangutans are killed in many parts of their range when hunting parties fail to kill any other animals. The fact that they are not targeted from the outset, but rather killed opportunistically, may explain why hunting was not perceived as a cause for concern for orangutan conservation until recently. About $5 \%$ of people interviewed across Borneo said that they had killed one or more orangutans (Davis et al., 2013; Meijaard et al., 2011a, 2011b). While the offtake rate may seem low, it is far above the sustainable level (Marshall et al., 2009; see Box 1.3).

In addition to being killed for their meat, orangutans are targeted by people who compete for the same resources, particularly when apes engage in crop foraging. They are also killed by poachers who seek to obtain younger individuals or babies for the national and international live animal trade. Based on conservative data, nearly 150 orangutans from Indonesia-mostly young orphans-enter the domestic and international trade every year (Stiles et al., 2013, p. 8). As late as the 1920 , orangutans were still killed by trophy hunters or headhunters who sought their skulls, or for traditional medicinal purposes (Rijksen and Meijaard, 1999).

\section{African Apes}

African apes-bonobos, chimpanzees and gorillas-are hunted across all countries where they occur in the wild, but the drivers and extent of the problem vary spatially across species and subspecies. West and Central Africa have the highest prevalence of ape hunting, with a few regional and local exceptions (Fa and Brown, 2009; Heinicke et al., 2019). While a dearth of empirical data precludes an accurate assessment of the impact of hunting on the decline of African apes, research demonstrates that hunting affects ape distribution and density and that the development of road networks, particularly in forested regions, exacerbates the problem (Hickey et al., 2013; Poulsen, Clark and Bolker, 2011; Strindberg et al., 2018; Vanthomme et al., 2013; Walsh et al., 2003).

In a few exceptional locations, cultural or religious taboos restrict the hunting and sale of ape parts for consumption, traditional medicine, fetishes and ceremonial events; in some protected areas, law enforcement or a research presence curtails such practices (Campbell et al., 2011; Kortlandt, 1986; Oates et al., 2007; Tagg et al., 2015; see Box 1.4). These exceptional cases do not necessarily protect apes from being killed, however, as local conditions-such as the influx of people who hold different beliefs and attitudes towards apes, ape tolerance levels, the effectiveness of law enforcement measures and the presence of researchers-may change over time. In spite of taboos against killing apes, for instance, villagers in certain 
locations have hired "external" hunters to kill chimpanzees as a way to deter other apes from consuming their crops (Brncic, Amarasekaran and McKenna, 2010).

Villagers may also attack apes if they are perceived as threats to their property, their safety or that of their children; when such "retaliatory" killings claim the lives of mothers, they can result in the capture of infant apes (Projet Primates, n.d.; Chimpanzee Conservation Center, unpublished data, 2012). Aside from being a by-product of hunting or "conflict" situations, the capture of infants is also driven by direct demand from mainly foreign buyers. Demand varies across species; in Africa, chimpanzees top the list (Stiles et al., 2013).

\section{Chimpanzees}

Of all African apes, chimpanzees have the widest distribution, as well as the largest population (see the Apes Overview). As a consequence, they also dominate the trade in live apes. An estimated 92 chimpanzees enter the live trade every year, compared to 7 bonobos and 14 gorillas (Stiles et al., 2013). The capture of a single chimpanzee infant implies the death of up to ten other individuals in the community; about one-quarter of all captured infants die soon after they are caught and many more do not survive the transit to their final destination (Hicks et al., 2010). Indeed, for every live chimpanzee delivered to a final recipient, 4-13 have lost their lives in the process.

The above-mentioned "retaliatory" attacks on chimpanzees can create a vicious circle, as people increasingly provoke apes, enhancing the risk that they will respond more aggressively during subsequent encounters (Hockings et al., 2010; McLennan and Hockings, 2016). Outside protected areas, in landscapes shared by chimpanzees and people, such situations can escalate the killing of apes and the consequent capture of infants-unless quickly managed.
Hunting pressure on chimpanzees varies across the four subspecies and within each subspecies' range, mainly because of variations in religious or cultural taboos against the killing and capture of chimpanzees and human activities across protected and unprotected areas. The majority of western chimpanzees (Pan troglodytes verus) live outside protected areas, which renders them all the more vulnerable to hunting. The population-estimated at $18,000-65,000$ individuals-is experiencing an annual rate of decline of 6\% (Kormos et al., 2003; Kühl et al., 2017).

A section of the range of the NigeriaCameroon chimpanzee (Pan t. ellioti) overlaps with a region characterized by high human population density. This area, which has witnessed significant habitat destruction and fragmentation in recent years, suffers from a lack of enforcement of hunting laws. As a result, hunting has worsened, exacerbated by the increased ease of access to firearms, enhanced transport routes and growing financial incentives for supplying urban wild meat markets in the region (Morgan et al., 2011). With fewer than 6,000 individuals, this subspecies will not be able to withstand the current hunting rates, which are 2-13 times higher than sustainable rates (Hughes et al., 2011; Oates et al., 2016).

Subsistence and especially commercial hunting have also been recognized as major threats to the conservation of central chimpanzees (Pan t. troglodytes), whose population comprises about 128,700 weaned individuals (Strindberg et al., 2018; Tutin et al., 2005). Artisanal and commercial mineral and oil extraction, transport and infrastructure development, such as roads and railways, and encroachment into forest areas via agriculture or logging activities have contributed to an increase in hunting pressure and activities across this subspecies' range (Arcus Foundation, 2014, 2015, 2018; Laurance et al., 2006). 
Photo: Over the past 20 years, Grauer's gorillas have suffered the most dramatic decrease of the four gorilla subspecies, largely due to hunting. (c) GRACE
Populations of the eastern chimpanzee (Pan t. schweinfurthii) comprise an estimated 181,000-256,000 individuals (Plumptre et al., 2016a). People hunt them across their range, primarily for meat consumption but also for traditional medicine, most prominently in the Democratic Republic of Congo (DRC) and the Central African Republic (Hicks et al., 2010; Plumptre et al., 2010). If mothers are killed, any infants are typically captured and kept alive to be traded. This illegal traffic of live chimpanzee orphans, from the DRC through East Africa and elsewhere on the continent, remains high, despite efforts to abate it (Hicks et al., 2010).

\section{Bonobos}

The DRC is home to all bonobos (Pan paniscus), whose population is estimated at 15,000-20,000 (IUCN and ICCN, 2012). Although ape species are fully protected under DRC law, they continue to be killed, mostly to meet the demand for wild meat in urban centers and to facilitate the capture of infants for the live animal trade, which occurs as a direct by-product of hunting (Nasi et al., 2008; Wilkie et al., 2011). The high presence of rebel factions and poorly remunerated soldiers also fuels demand (Fruth, Williamson and Richardson, 2013). In only a few areas are bonobos buffered against hunting due to local cultural taboos against their killing and consumption (Inogwabini et al., 2008; Lingomo and Kimura, 2009). Even in those areas, however, years of civil unrest, the movement of people across the country and poor law enforcement are weakening the influence of local taboos that protect bonobos from being killed or captured (Fruth et al., 2016).

\section{Gorillas}

Available information reveals that the impact of hunting is high, yet variable, among the two species and four subspecies of gorilla. Overall, gorillas are easier to kill with guns than chimpanzees or bonobos because they are more terrestrial and live in more cohesive social groups (Plumptre et al., 2016b; Strindberg et al., 2018).

Over the past 20 years, Grauer's gorillas (Gorilla beringei graueri) have suffered the most dramatic decrease of the four gorilla subspecies, largely due to hunting. This subspecies has experienced a precipitous decline of nearly $80 \%$, from an estimated 16,900 gorillas in the mid-1990s to around 3,800 in 2015. This sharp drop is largely due to hunting by artisanal miners in areas controlled by armed militias (Plumptre et al., 2016b). In the absence of intense conservation interventions, this subspecies could go extinct in the next 20 years. The impact of hunting is exemplified by the 14 orphaned gorillas currently living in the GRACE (Gorilla Rehabilitation and Conservation Education Center) sanctuary in the eastern DRC (GRACE, n.d.).

In contrast, mountain gorillas (Gorilla b. beringei) experience relatively low levels of hunting, largely due to the taboo against eating gorillas and other primates in the communities surrounding their habitat (Robbins et al., 2011). Mountain gorillas are the only subspecies of ape known to have a stable or increasing population size (Hickey et al., 2019). ${ }^{6}$ Nevertheless, in 1967-2008, 26 habituated gorillas were killed in the Virunga Massif; they represent $12 \%$ of all mortality during that time. These killings probably reduced the growth rate of the habituated groups by about $1 \%$ annually. Of those 26 gorillas, 3 died due to snares, 15 were shot by militias, and the remaining 8 were killed for various reasons, including the pet trade, efforts to stop crop raiding, and the wild meat trade (Robbins et al., 2011). Furthermore, law enforcement confiscated six young mountain gorillas from poachers between 2004 and 2017, confirming that there is a demand for infant gorillas and that killing adults allows poachers to capture orphaned infants (Virunga Alliance, n.d.). 
Western lowland gorillas (Gorilla gorilla gorilla) are the most numerous of the four subspecies, with an estimated 360,000 individuals. From 2005 to 2013 , the population declined at an estimated annual rate of $2.7 \%$, due mainly to illegal killing, habitat destruction, and disease. If this rate of decline continues, the population will decrease by more than $80 \%$ in the next 60 years. The density of gorillas was significantly lower in areas that lack law enforcement guards; it also declined as the local human density increased. Both of these factors substantiate that hunting is the main cause of the lower density of gorillas. As approximately $75 \%$ of western lowland gorillas live outside protected areas, a rapid decline in population size can only be avoided through enhanced law enforcement in those areas. The density of gorillas is higher wherever there is a taboo against eating them, yet these areas account for only about $1 \%$ of their range (Strindberg et al., 2018).

Several small-scale studies provide further evidence of the high impact of hunting on western lowland gorillas. Poulson, Clark and Bolker (2011) find that the density of gorillas was $61 \%$ lower in areas that had hunting and logging compared to areas with only logging. A study that compiled hunting rates from 36 sites in Central Africa estimates that 3.5 gorillas were killed per year in areas with only 0.7 gorillas per $\mathrm{km}^{2}$ (7o hectares), a relatively low density ( $\mathrm{Fa}$, Ryan and Bell, 2005). Surveys of hunters in Cameroon found that great apes were not among the top ten species of wild meat hunted, but about $25 \%$ of the hunters had killed at least one gorilla or chimpanzee. The low rate of killing apes reflects a low number of encounters (Tagg et al., 2018; Wright and Priston, 2010).

Only about 300 Cross River gorillas (Gorilla g. diehli) remain in the wild, scattered in a highly fragmented landscape that is characterized by high human pressure. Hunting probably contributes to the restricted range of these gorillas as much as habitat loss (Bergl et al., 2012). The level of human disturbance - including hunting pressure-can determine whether Cross River gorillas occur in certain areas of suitable ecological habitat (Imong et al., 2014). Modeling interventions to conserve these gorillas showed that an increase in law enforcement and a decrease in hunting pressure lead to the best scenario for recovery of this fragmented population (Imong et al., 2016).

\section{Why Apes Are Particularly Sensitive to Hunting}

\section{Slow Breeding and Population Viability Analysis}

All apes are particularly sensitive to hunting because they have slow life histories and low reproductive rates (Barelli et al., 2007; Cheyne, 2010; Cheyne and Chivers, 2006; Emery Thompson et al., 2007; Furuichi et al., 1998; Savini, Boesch and Reichard, 2008; Sugiyama and Fujita, 2011). On average, females start to reproduce between the ages of 9 and 15 years and have one offspring every 3-9 years; for infants up to 3 years, mortality rates vary from $25 \%$ to more than $50 \%$, depending on species and populations (Mittermeier and Wilson, 2013). As a consequence, a slight increase in mortality rates — such as may be caused by hunting — can have a significant and rapid impact on population viability, including through population decline, the cumulative elimination of isolated populations and, in the most severe cases, species extinction (Carlsen et al., 2012; Fan et al., 2013; Smith et al., 2018; Turvey et al., 2015).

A recent population viability analysis (PVA) for the western chimpanzee revealed that all populations with fewer than 100 individuals have at least a $50 \%$ chance of extinction over the next 100 years if they 
experience a $3 \%$ annual loss of individualsbe it due to hunting, snaring, disease or other causes (Carlsen et al., 2012). ${ }^{7}$ Under these conditions, and given their slow reproductive cycles, the rate of removal of reproductive adults is greater than the rate of replacement. Viable populations of 250 to 1,000 chimpan- zees may be large enough to persist with a decline in genetic diversity after 100 years, yet even these will ultimately become extinct if the annual rate of removal exceeds $2-3 \%$, unless efforts are made to curb or eliminate the factors that influence their removal, such as hunting (Carlsen et al., 2012).

\section{BOX 1.4}

\section{Culture and Hunting of Apes}

Cultural practices and religion can have a positive or negative effect on wild apes. In the many parts of Sumatra and Borneo that are dominated by Muslim communities, for example, ape hunting is less severe than in other regions (Davis et al., 2013). In some areas, it is taboo to kill, eat or capture apes; such traditional taboos are often linked to the recognition of apes' resemblance to humans or their presence at sacred sites. These taboos are of particular value to the conservation of apes. Research indicates that in the absence of hunting, chimpanzees and orangutans can persist in areas of anthropogenic influence, including highly degraded landscapes dominated by agriculture and interspersed with remnant forest fragments (Blanco and Waltert, 2013; Campbell-Smith et al., 2011a; Garriga et al., 2019; Hockings et al., 2012; Madden, 2006).

Taboos have enabled chimpanzee populations to persist outside protected areas, as is the case in some parts of Guinea, Guinea-Bissau and Sierra Leone (Bessa, Sousa and Hockings, 2015; Brncic, Amarasekaran and McKenna, 2010; Kormos et al., 2003; Matsuzawa, Humle and Sugiyama, 2011). In those countries and other parts of western equatorial Africa, the densities of chimpanzees and gorillas are also much higher in areas where local communities hold taboos against eating their meat (Heinicke et al., 2019; Strindberg et al., 2018). In this region, such taboos benefit chimpanzees more than they do gorillas; among 59 sites surveyed, most people across 6 sites did not eat chimpanzee, while eating gorilla was generally avoided in only 3 sites (Hicks et al., 2010).

Taboos may also vary with reference to local ape species; for example, in the extreme southwestern part of Gabon, one ethnic group traditionally does not eat chimpanzees, although members will consume gorilla meat. In northern Central Africa, women of certain ethnic groups reportedly refuse to cook or eat ape meat, for fear of giving birth to babies with "big ears." In other parts of the region, people have a taboo against eating chimpanzee meat, as they consider themselves to be descendants of a union of a chimpanzee and a human (Hicks et al., 2010).

In some regions, the strong belief in shapeshifting or animal transformation has benefited apes. Hunters in certain parts of Cameroon are afraid to kill gorillas or chimpanzees because they are worried that they might kill a person instead
(Wright and Priston, 2010). In the rare event that a chimpanzee attacks a person, such beliefs can redirect blame on people, thus minimizing any risk of retaliation for apes, ${ }^{8}$ yet potentially fueling intrahuman conflict instead. As a result, people's attitudes and behavior towards apes may actually worsen. Indeed, with the influx of migrants who may not hold the same beliefs as the local communities, and with the growing transportation networks and access to vehicles that facilitate the supply of wild meat to urban centers, such beliefs and taboos alone cannot protect apes from being killed.

The introduction of new belief systems may also erode traditional ones. A case in point is the growing popularity of the recently established religious sect of Branhamism in the northern DRC. The sect, which adheres to the doctrine of US prophet William Branham, appears to be weakening traditional prohibitions against the consumption of chimpanzee meat (Hicks et al., 2010).

In some cases, cultural practices and beliefs may also act as drivers of killing, whether for the consumption of meat or the use of body parts in traditional medicine and witchcraft. In central Sabah, some ethnic groups use orangutan parts to heal broken bones; in parts of West Africa, chimpanzee body parts are valuable fetishes that are thought to provide hunters with strength and protection; and in areas of equatorial Africa, certain gorilla body parts, namely the chest, hands and ribs, are believed to grant strength and courage, while ground chimpanzee bone is believed to cure wounds and confer strength on newborns (Hicks et al., 2010; Tagg et al., 2018). In the northern DRC, chimpanzee meat is a popular ingredient in stews and is sold openly in urban markets (Hicks et al., 2010); meanwhile, in Indonesia's Mentawai Islands, the hunting of gibbons is embedded in local people's culture (Quinten et al., 2014).

Given that cultural beliefs and practices shape behavior and attitudes, they are critical to understanding how to prevent the killing of apes. However, they are also highly dynamic and not necessarily durable: they can be modified extensively by the loss of traditional culture, new fashions and social trends, and the demand for apes and ape products. Efforts to encourage long-term positive behavior towards apes and to combat beliefs that endanger them thus require collaboration with social scientists, anthropologists and traditional leaders.

For more information on the cultural drivers behind the killing, capture and trade in apes, see Chapter 2. 


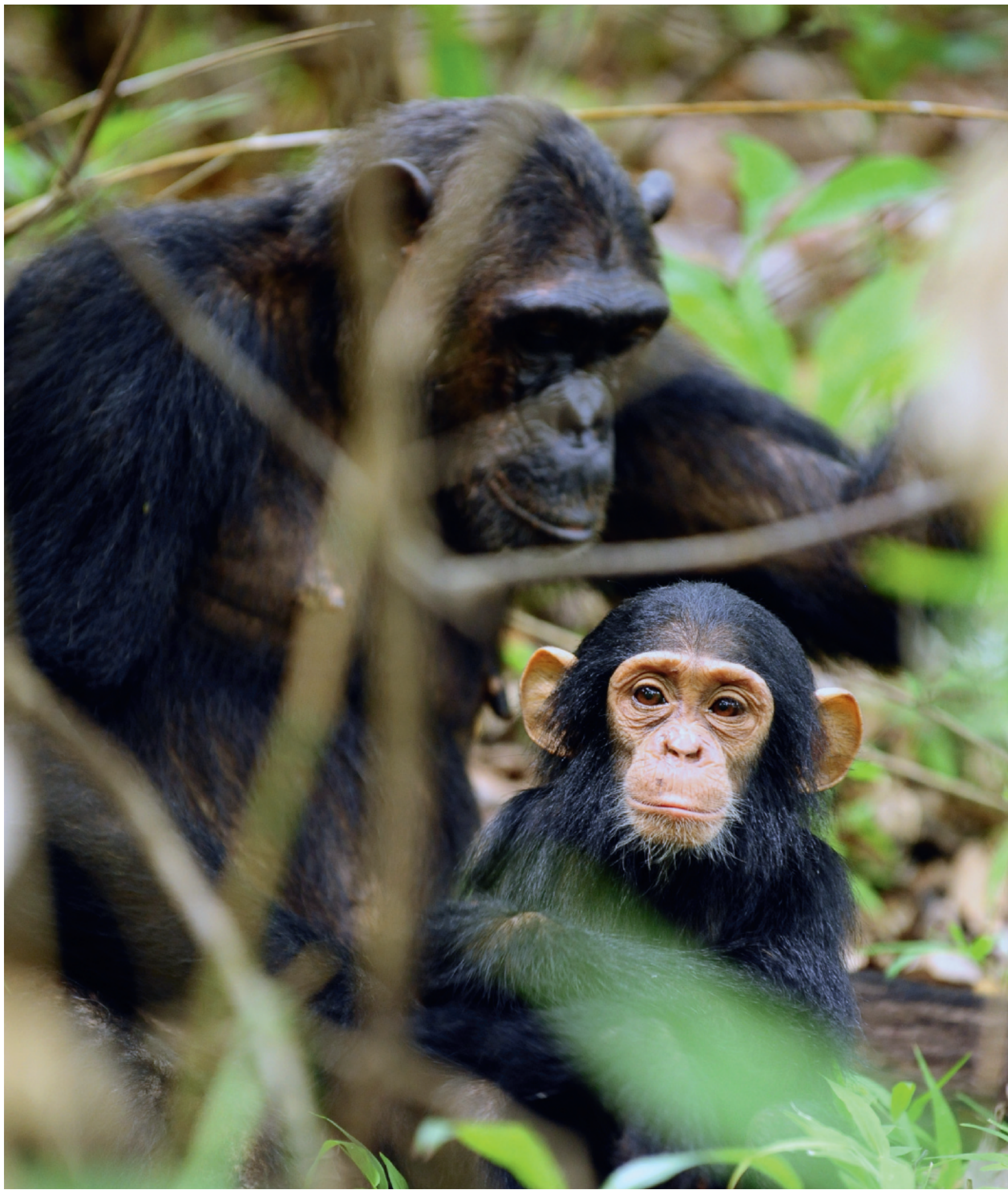


Since many remnant populations of moloch gibbon are isolated and fragmented, these populations are good case studies for long-term viability under different anthropogenic pressures (Smith et al., 2018). Three areas that harbor moloch gibbon populations were selected for a PVA: one that showed potential for population increase; one that comprised potentially fragmented populations; and one unprotected forest area that could experience substantial levels of poaching, such as hunting for the illegal pet trade. The PVA results indicate that all three moloch gibbon populations are likely to go extinct within 100 years if hunting and deforestation rates continue at the modeled rate-that is, if hunting costs the population 4-6 adults and 4-6 juveniles per year, and if deforestation causes their habitat to shrink by $1 \%$ per year. If both hunting and deforestation rates were to be minimized, however, all three populations would be large enough to persist and maintain high genetic diversity over the next 100 years.

A population reaches a "point of no return" when the number of apes falls beneath a given threshold, below which inbreeding, a subsequent collapse in reproduction and, ultimately, a loss of viability lead to extinction. Hainan gibbons are among the rarest mammals alive today, yet they have persisted for more than 30 years at the relatively low population size of about 25 individuals-without human intervention (Bryant et al., 2015). A PVA carried out for moloch gibbons in three areas in Indonesiathe Dieng Plateau, Mount Halimun Salak National Park and Ujung Kulon National Park-modeled scenarios based on fragmented populations of $25-75$ individuals. The findings suggest that such small populations face a greater risk of extinction than larger populations because they are more sensitive to increased levels of annual hunting and persistent rates of deforestation, and because they exhibit higher rates of mortality and loss of genetic diversity (Smith et al., 2018). Smaller populations would thus benefit from increased protection, and possibly from periodic genetic supplementation via translocation.

A recent population and habitat viability assessment (PHVA) conducted for orangutans establishes that a minimum population size of 150 individuals for Sumatra and 100 for Borneo is necessary to secure a viable population-one exposed to less than a $1 \%$ risk of extinction over 100 years and less than $10 \%$ over 500 years. A minimum of 200 individuals would be necessary to retain $90 \%$ of genetic diversity over a 500-year period. Based on the current knowledge of the species' ecology, the PHVA indicates that growth would be limited to $1.4 \%$ per year for the Sumatran species and 1.6\% per year for the Bornean species. It shows that a rate of continuous loss of $1 \%$ or more would be unsustainable and would lead any population to its demise. In other words, an orangutan population faces a high risk of extinction if more than $1 \%$ of its individuals are killed every year (which is typically the case today); it takes a very long time for any population to recover following a hunting event (UtamiAtmoko et al., 2019).

\section{Ape Social Systems as Risk Amplifiers}

Some aspects of the social systems of apes can amplify the impact of hunting. The social impacts of killings are most marked among gorillas and the other African great apes, largely because they are more social than Asian apes. As noted above, the killing of a silverback male can lead to infanticide and group disintegration (Kalpers et al., 2003; Robbins et al., 2013; Watts, 1989). Destabilization of the male hierarchical structure in chimpanzees can increase stress
Photo: All apes are particularly sensitive to hunting because they have slow life histories and low reproductive rates. Eastern chimpanzees, Mahale Mountains National Park, Tanzania. (C) Slobodan Randjelovic/ Arcus Foundation 
levels and intragroup lethal aggression (Pruetz et al., 2017; Wilson et al., 2014b). At Wamba in the DRC, an entire group of bonobos exhibited concern and distress in response to the snaring of a group member at the periphery of their home range. Some individuals tried to help dislodge the snare; failing to disentangle the injured bonobo completely, they returned to the safety of their core area for the night and traveled back $1.8 \mathrm{~km}$ to check on him the next day, only to find he had disappeared (Tokuyama et al., 2012).

In contrast, the direct social impact of killing on semi-solitary orangutans seems to be minimal, although the killing of resident females disrupts the complex network of females in any given area. Research suggests that unrelated females may settle in a disturbed area and further destabilize the local social network. ${ }^{9}$ Given the paucity of data available on this topic, the long-term consequences of such events on survival and breeding rates are unknown, although, as discussed above, population and habitat viability assessment simulations can offer some insight.

What is clear is that, absent hunting, great apes could persist in areas of anthropogenic influence, including fragmented forest-farm mosaics. Such has been the case for the orangutan population in Kinabatangan and several chimpanzee populations in Guinea and Sierra Leone, as well as mountain gorillas surrounded by areas of high human population density (Ancrenaz et al., 2015; Brncic, Amarasekaran and McKenna, 2010; Campbell-Smith et al., 2011b; Hockings and McLennan, 2012; Madden, 2006; Robbins et al., 2011). Although the impact of hunting on the long-term viability of populations can be estimated using predictive models, more research is needed to build a better understanding of the social processes that support the viability of these groups and populations.

\section{Ecological Impacts of Ape Hunting}

Apes are key players in the maintenance of intact ecosystems. Due to their large size, great apes are particularly efficient dispersers of large seeds $(>1 \mathrm{~cm})$, which are not easily dispersed by smaller animals (Leighton, 1993; Tutin et al., 1991). After feeding on large fruit and swallowing the seeds, apes regurgitate or defecate them, sometimes a distance away from the mother trees (Beaune et al., 2013; Chapman and Onderdonk, 1998; Rogers et al., 1998, 2004; Voysey et al., 1999a, 1999b; Wilson et al., 2014a; Wrangham, Chapman and Chapman, 1994). At Kibale, chimpanzees swallowed and defecated seeds from $82 \%$ of the fruit species they ate; in Borneo, gibbons did the same for at least seven plant species (Lambert, 1998; McConkey, 2000). At LuiKotale in the DRC, bonobos disperse the seeds of about $40 \%$ of the local trees; when these seeds fall straight to the ground instead of being dispersed by the apes, the vast majority fail to germinate and mature successfully, indicating that seed dispersal at this site is critical to tree conservation (Beaune, 2015).

Not only are apes good seed dispersing agents, but they also improve the germination and survival rates of seeds that they swallow and defecate for certain plant species (Ancrenaz, Lackman-Ancrenaz and Elahan, 2006; Beaune, 2015; Chapman et al., 2004). In Borneo, unarmed seeds of 23 plant species were recovered from the feces of orangutans (Galdikas, 1982). In view of their role as dispersers, orangutans have been described as "gardeners or cultivators of much of their own provisions" in the forest (Rijksen and Meijaard, 1999, p. 55).

When apes are removed from the wild, so is their seed dispersing function. While 
apes have been extirpated, if local threats are mitigated. ${ }^{10}$

In spite of recent efforts to improve the enforcement of laws that forbid the trade in live apes, orphans continue to arrive at rescue centers. At least 23 sanctuaries for confiscated apes are operating in Africa and about 10 take in orangutans in Asia (PASA, 2018). The vast majority of sanctuaries are at capacity and expensive to run. While they are sometimes criticized for directing resources away from wild habitat, they provide critical support for law enforcement, animal welfare, and public education (Schoene and Brend, 2002; Sherman and Greer, 2018, pp. 227-55; Wilson et al., 2014a).

In Southeast Asia, young rescued orangutans are typically sent to rehabilitation centers, while older individuals tend to be translocated immediately, without proper assessment or monitoring (J. Sherman and D. Greer, unpublished data, 2018). Translocation often disrupts the status and hampers the connectivity of orangutan meta-populations, thereby jeopardizing their long-term viability. Moreover, it is often unclear whether the area in which orangutans are released can sustain additional individuals, and whether there is a risk of disease transmission between released animals and recipient populations (Beck et al., 2007; Campbell, Cheyne and Rawson, 2015; Tutin et al., 2001). Decisions to translocate or rescue are often driven by a fear that individuals will not survive as a result of extensive forest loss or hunting. To avoid the above-mentioned problems, however, translocation is best used as a last
BOX 1.5

\section{Wild Meat as a Source of Major Diseases}

Hunting and the consumption of wild great apes represent a major risk factor for disease emergence. Due in part to widespread hunting for wild meat, zoonotic pathogens-ones that are communicable from animals to humans-account for a large proportion of emerging infectious diseases and pose a serious threat to global human health. The risk is exacerbated by major ecological changes, greater intrusion of humans into pristine forest areas, and a human population that may be especially susceptible to disease due to poor health and preexisting infections, such as HIV and parasites (Jones et al., 2008).

With respect to the wild meat trade and consumption, great apes are of special concern because their close evolutionary relationship with humans-along with their similar physiology - facilitates pathogen transmission. In fact, numerous zoonotic infectious agents linked to hunting great apes have had an important and sometimes global impact on human health (Gillespie, Nunn and Leendertz, 2008). The most prominent examples are simian immunodeficiency viruses, which have crossed the species barrier into humans on multiple occasions, giving rise to different human immunodeficiency virus groups and resulting in one of the most serious public health challenges - the AIDS pandemic (Hahn et al., 2000). Other viruses, such as adenoviruses, which are associated with respiratory illnesses, also originate from great apes (Hoppe et al., 2015; Richard et al., 2016). Many more transmissions have most probably occurred but have yet to be discovered and documented.
In other cases, apes are not the reservoir of a virus, but rather the victims. One example is the highly pathogenic Ebola virus, which has emerged from wild great apes on several occasions. Records show that epidemics have occurred among western lowland gorillas (Gorilla gorilla gorilla), central chimpanzees (Pan troglodytes troglodytes) and western chimpanzees (Pan t. verus) (Leendertz et al., 2016). The extent of these epidemics in great apes is not well documented, but carcass analysis and monitoring data indicate that Ebola virus infections may have led to major die-offs in several regions of Central Africa (Bermejo et al., 2006).

Numerous epidemics in humans have emerged as a consequence of exposure to great ape carcasses (individuals found dead or killed), demonstrating a direct link between epidemics in great apes and humans. The risk of spillover to humans is thus directly linked to the extent of the outbreaks in great apes (Leendertz et al., 2016). The case of the Ebola virus is just one example of the transmission of an acute disease-causing pathogen. It is highly likely that other pathogens are also transmitted to people following the same pathway; likely candidates include the monkeypox viruses and the anthrax-causing bacterium Bacillus cereus biovar anthracis (Hoffmann et al., 2017).

A reduction in the hunting and butchering of great apes is of great importance not only to their conservation, but also to public health. In addition, systematic health monitoring of great ape populations can serve as a tool for early warning and can ultimately lead to the mobilization of local and even global health resources to fight disease in great apes and humans (Calvignac-Spencer et al., 2012). 
resort, if an animal's life is truly at risk. Educational and law enforcement efforts are needed to tackle the root of the problem -the removal of apes from the wild.

Hunting and snaring also raise ethical and legal issues. If a bullet or trap injures an ape, for instance, must veterinary interventions be organized? If so, by whom and using whose budget? Similarly, if apes contract a disease as a result of exposure to hunters or other people, must they be treated or vaccinated to minimize the risks of disease transmission? The use of apes for tourism purposes and for research activities raises further questions. In these contexts, responsibilities may arise given that habituated apes are more vulnerable to poachers, for instance (Macfie and Williamson, 2010).

Moreover, various groups have raised ethical considerations regarding the killing, capture and trade in apes. In view of their advanced emotional and intellectual development, some advocates propose that great apes be accorded the same rights to life, the protection of individual liberty and the prohibition of torture that humans enjoy (Cavalieri and Singer, 1993; see Chapter 8).

\section{Ape-based Economies}

In the ape range-states of Africa and Asia, people have given rise to a disparate set of ape-based economies: a legal one that comprises tourism, research and conservation, and an illegal one that revolves around the trade in meat, parts and live apes. As the illegal economy expands, it increasingly jeopardizes the legal one.

\section{Legal Ape-based Economies}

On a global scale, the extirpation of ape populations due to hunting comes at a significant socioeconomic cost. Indeed, given the iconic status of apes, their presence in an area can attract tourism or research opportunities, which can benefit local industries and create employment for local residents (Drewry, 1997; Kondgen et al., 2008; Macfie and Williamson, 2010; Marshall et al., 2016; Muehlenbein and Ancrenaz, 2009; Russell, 2001). In some countries, great ape viewing and related nature-based tourism is an important contributor to the conservation of apes and their habitat, as well as the national economy (Maekawa et al., 2015). Mountain gorillas draw nearly 50,000 people per year to Rwanda and Uganda, ${ }^{11}$ where tourists currently pay between US $\$ 600$ and US $\$ 1,500$ for a one-hour visit with apes (Uganda Wildlife Authority, n.d.; Visit Rwanda, n.d.).

While such revenues may surpass those generated through agricultural land uses, there is scope to improve benefit-sharing mechanisms with local communities and to enhance the value of coexisting alongside apes and other wildlife species (Ahebwa, van der Duim and Sandbrook, 2012; Naidoo and Adamowicz, 2005). At this stage, not all ecotourism practitioners follow the IUCN Guidelines, even though doing so could help to promote ape conservation (Macfie and Williamson, 2010).

\section{Illegal Ape-based Economies}

Meanwhile, the illegal trade in apes is an increasingly profitable business. A recent report by Global Financial Integrity estimates the current rates paid for infant great apes, as well as the poachers' and retailers' cuts (Clough and May, 2018). Orangutan poachers earn between US $\$ 8$ and US $\$ 121$ per animal; traders operating at the village level receive between US $\$ 140$ and US $\$ 385$; and city-based traders can pocket US $\$ 454$ (for a domestic sale) to more than US\$20,000 (for an international sale). Local Indonesian consumers pay up to US $\$ 2,000$ and international buyers spend up to US\$70,000 
Photo: Given the iconic status of apes, their presence in an area can attract tourism or research opportunities, which can benefit local industries and create employment for local residents. (C) Mathieu Asselin/ Arcus Foundation per infant, indicating that the financial gain for traders up the market chain is substantial. Based on the estimated number of great apes entering the live trade every year7 bonobos, 14 gorillas, 92 chimpanzees and 146 orangutans (Stiles et al., 2013) - the annual global market value is US $\$ 147,000$ to US $\$ 301,000$ for bonobos, US $\$ 560,000$ to US $\$ 2.1$ million for gorillas, US $\$ 1.4$ million to US $\$ 6.4$ million for chimpanzees and US $\$ 277,000$ to US $\$ 10$ million for orangutans.

These rates are not likely to decrease as long as owning an ape continues to be seen as a symbol of high social status, or as long as niche industries exploit animals for profit (J.Head, personal communication, 2018; see Chapter 4). Indeed, the demand for live captures appears to be on the rise as apes continue to be used as photo props in tourist settings, and as performers in zoos or amusement parks, particularly in Asia (Clough and May, 2018).

Similarly, killing apes for meat is associated with a substantial profit per shot, as adult ape bodies provide a lot of meat $(\mathrm{Fa}$, Ryan and Bell, 2005). In Cameroon, gorillas tend to be divided into 18-20 "cuts" of meat and chimpanzees into 10-12 cuts, each of which can fetch US\$2-10 (Tagg et al., 2018).

All in all, the illegal trade in great apes is a lucrative and low-risk business for those operating at the middle and upper levels, in large part because governments are doing little to address the problem. The market thrives due to a host of deficiencies: significant gaps in the enforcement of the Convention on International Trade in Endangered Species of Wild Fauna and Flora (CITES), the low rate of prosecutions, the limited dissuasive effect of successful prosecutions, publicand private-sector corruption, insufficient resources for investigators in developing and developed countries, local community challenges, and abuse of social media and financial service companies. For more information on the socioeconomic drivers of the meat, parts and live animal trade, see Chapters 3 and 4.

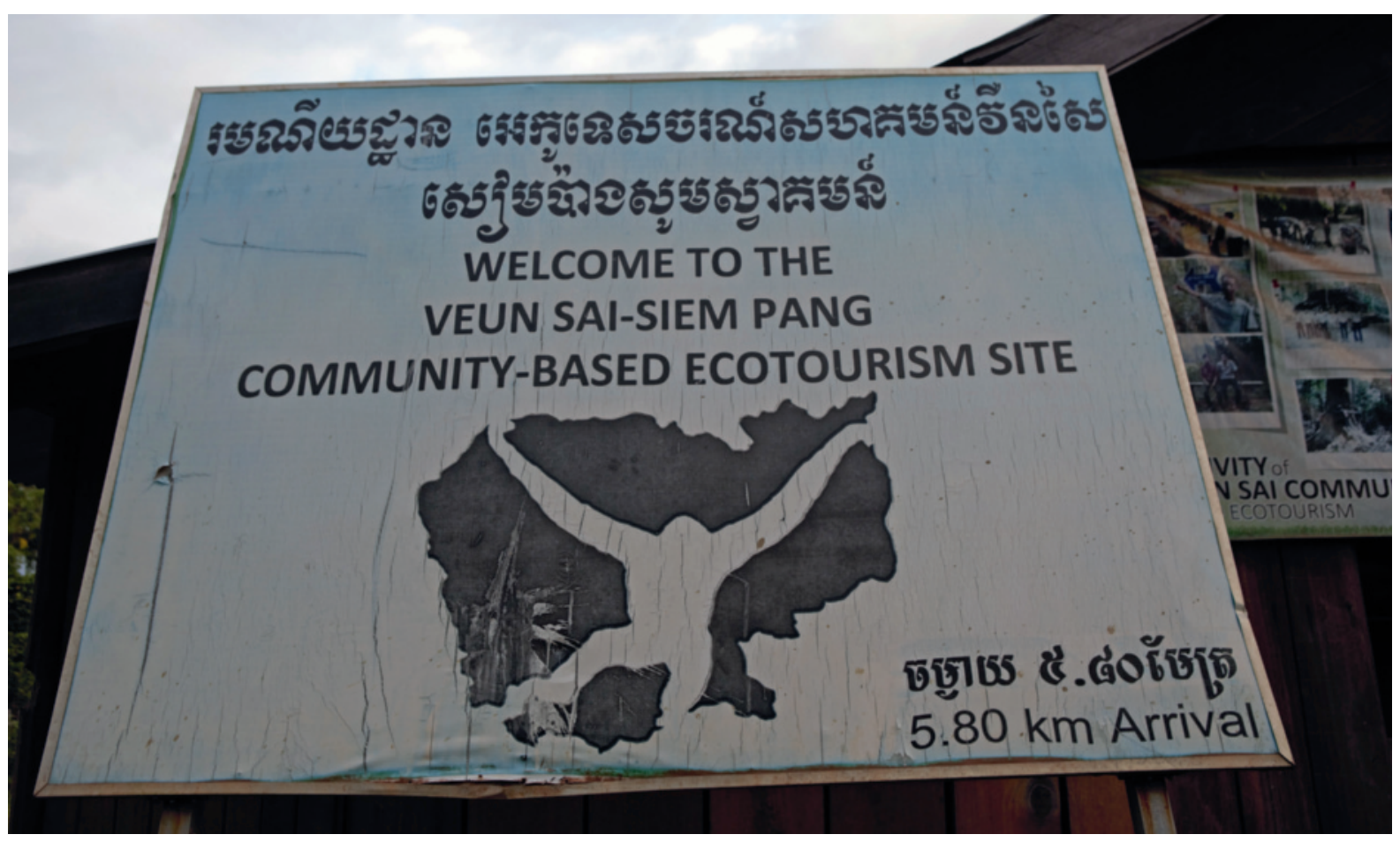




\section{Conclusion}

The hunting of apes is a major driver of population decline and extinction. In addition to reducing the absolute size of ape populations, it has far-reaching consequences on ape habitat as well as on the human communities living alongside or near the apes and beyond. The development of adequate mitigating strategies is a complex task, one that is further complicated by the dearth of information on all aspects of the issue.

Relatively little is known about the scale of ape hunting, as it is difficult to quantify illegal activities, particularly in remote areas with limited law enforcement. While research indicates that the underlying reasons for hunting apes are multifaceted, further studies are needed to identify enablers and drivers of activities such as hunting for consumption and "retaliatory" killings. The findings could be used in modeling future trends of the impact of hunting and ways to tackle it. Additional research is also required to explain why some people are prone to consume wild ape meat, and to inform programs and policies designed to enhance people's tolerance of apes, including behavioral change campaigns, compensation schemes and alternative livelihoods activities. A better understanding of the impact of hunting on apes and their habitat is key to ensuring their survival in the wild.

\section{Acknowledgments}

Principal authors: Marc Ancrenaz, ${ }^{12}$ Susan M. Cheyne, ${ }^{13}$ Tatyana Humle ${ }^{14}$ and Martha M. Robbins ${ }^{15}$

Contributor Box 1.5: Fabian Leendertz ${ }^{16}$

\section{Endnotes}

1 The cause of the injuries was presumed for three of the chimpanzees and confirmed for the other two.

2

Rankin, E., Tzanopoulos, J., Amarekaran, B., Colin, C., Cuadrado, L. and Humle, T. (manuscript in preparation). Recent deforestation drives the illegal capture of chimpanzees in West Africa.
Clake, D., Tzanopoulos, J., Amarekaran, B., Humle, T. (manuscript in preparation). Drivers of intolerance towards chimpanzee utilization of the oil palm in Sierra Leone, West Africa.

3 For details, see Chan et al. (2017); Fan (2017); Hallam et al. (2016); Hoàn, Dũng and Trường (2016); Phoonjampa and Brockelman (2008); Sarma, Krishna and Kumar (2015); Smith et al. (2018); Whittaker, Morales and Melnick (2003); and Yin et al. (2016).

4 Internal report on work undertaken by WWF Myanmar and Gibbon Protection Society Malaysia, 2018 , seen by the author.

5 Cheyne, S.M., Smith, J.H., Llano Sanchez, K. and Moore, R. (manuscript in preparation) Tackling the illegal online trade of Indonesian small apes.

6 Granjon, A.C., Robbins, M.M., Arinaitwe, J., Cranfield, M.R., Eckardt, W., Mburanumwe, I., Musana, A., Robbins, A.M., Roy, J., Vigilant, L. and Hickey, J.R. (manuscript in preparation) Increased survey effort and intrinsic growth contribute to the largest recorded mountain gorilla population.

7 The model assumed equal chances of removal for adult males and females and the removal of one infant for every two adult females (Carlsen et al., 2012).

8 Shapeshifting beliefs prevail among the Manon people of Bossou, Guinea (Hockings et al., 2010).

9 Field observations by one of the authors and other staff members at HUTAN-Kinabatangan Orangutan Conservation Programme, Sabah, Malaysian Borneo, 2018-19.

10 See Beck et al. (2007); Brockelman and Osterberg (2015); Campbell, Cheyne and Rawson (2015); Cheyne, Campbell and Payne (2012); Cheyne, Chivers and Sugardjito (2008); Farmer, BuchananSmith and Jamart (2006); Farmer and Jamart (2002); Humle et al. (2011); McRae (2000); Russon (2002); Trayford and Farmer (2012); and Wilson et al. (2014a).

11 Visitor numbers based on author conversations with park staff (Bwindi Impenetrable Forest, Mgahinga and Volcanoes), 2018.

12 HUTAN-Kinabatangan Orang-utan Conservation Programme (www.hutan.org.my).

13 Borneo Nature Foundation (www.borneonaturefoundation.org).

14 University of Kent (www.kent.ac.uk/sac).

15 Max Planck Institute for Evolutionary Anthropology (www.eva.mpg.de).

16 Robert Koch Institute (www.rki.de) 